\title{
Medical Educator Roles of the Future
}

\section{Poh-Sun Goh ${ }^{1}$}

Accepted: 21 September 2020 / Published online: 30 September 2020

(C) International Association of Medical Science Educators 2020

This commentary is based on a plenary presentation on this topic at this year's IAMSE 2020 Virtual Conference. The presentation slides and full narration, as well as the cited reference material, are available on a customised blog, shared with conference participants two weeks before the presentation [1]. This allowed the majority of the session to be spent on an interactive question-and-answer format.

'The aim of the presentation was to examine how "new" methods and platforms for displaying information, engaging an audience, extending and expanding the cognitive presence of "the instructor", and increasingly "guide" will transform the learning experience, and training outcomes, of our educational efforts; and also explore how these same technologies, which include artificial intelligence (AI) and machine learning, virtual reality (VR) and augmented reality (AR), online and reimagined out-of-the-simulation-center skill training experiences (inspired and modelled after gaming platforms), can augment, enhance, and transform how we educate and train healthcare professionals, along the whole continuum of learning, from undergraduate learning, through postgraduate training, to lifelong learning and continuing professional development settings'. [1].

What are medical educator roles of the future, and how can near future technology impact how we educate healthcare professionals and the way they provide care? What are useful mental approaches we can use to think about and plan our strategies in this area? A useful starting point is to always think about 'Why', before 'What' and 'How'. Focus on the outcomes of the learning or training process, the 'Why', before thinking about the instructional content and tools we might use, the 'What', and instructional approach, the 'How'. Think of the 'job to be done' before picking up the

Poh-Sun Goh

dnrgohps@nus.edu.sg

1 Department of Diagnostic Radiology, Yong Loo Lin School of Medicine, National University of Singapore, 5 Lower Kent Ridge Rd, Level 3 National University Hospital Main Building, Singapore 119074, Singapore appropriate tool [2]. We also build on time honoured teaching and learning traditions from our past, as well evidence and scholarship of effective teaching and learning approaches. Technology allows us to add to, improve and potentially transform teaching practice [3]. We can imagine AR as an extension of the physical guidebook in the field or practice setting, VR as an extension of videos, online simulation and serious games as an extension of laboratory and physical simulation centre practice with feedback training, and $\mathrm{AI}$ and machine learning as an extension of the tutor or instructor at our side. AR can be envisioned to have a particularly useful role in workplace and informal learning settings, in later undergraduate, postgraduate and lifelong learning, to look things up and refresh our memory. VR and online simulation can have roles in the initial learning stage to get access to and safely navigate workplace settings. As we think about and experiment with the new, always focus on what is useful, and our fundamental pedagogical and instructional intention, as well as adopt a scholarly mindset and approach, to use evidence and the literature, gather information for evaluation and add to discourse and educational scholarship [4].

I believe that we can glimpse the future, where our roles and impact as educators are assisted, augmented and scaled up as educators by paying attention to media reports of trending and new innovations, as well as conference papers and presentations. Indeed, the COVID-19 pandemic has accelerated the adoption and acceptance of technology to reach out to and connect us. This is anchored on the use of digital content, accessible online; the Internet which provides access to this content; software, mobile apps and platforms providing structured search, access and guidance; and mobile devices allowing us to access this [5]. Why do some technologies reach the tipping point and get widely adopted, whilst others languish in 'trough of disillusionment' after a 'peak of inflated expectations' [6]. Empirical observation, personal experience and review of the history of adoption of learning technologies suggest that widespread acceptance and adoption occur when usable, useful, accessible, convenient-to-use, relatively low-cost technology tools and platforms become widely available [7]. 
When thinking about our role, and use of technology, focus on the learner, the aim of the learning process and how learners interact with the educational content; to assimilate this, develop knowledge, skills and attitudes, and transfer this into practice. A simple way of thinking about the teaching process is to 'present content, provide practice and feedback, and assess learning' [8]. 'It is the learning process and training outcome that we should be focused on as educators. The technology is there to assist us'. [1].

Simply put, a learner sees, hears and has experiences. The idea is to get the learner to actively engage with the content, in an iterative learning and training experience. To take notes, review these notes, recall key ideas, link new to existing knowledge, use new knowledge to solve clinical problems, practice clinical skills, as well as to nurture and strengthen core attitudes like empathy and professionalism, as well as teamwork and communication skills, and transfer this into practice. Effective learning is a repetitive, iterative and cumulative process [9]. Technology, like AR and VR, allows learners to visualise content and experience practice settings. Online simulation and serious games allow learners to practice individual and team-based skills. To see, and do. Artificial intelligence and machine learning, and instructors in their role as trainers and coaches, give feedback and provide dynamic, personalised customisation of learning content and training experiences [10]. As educators, we should focus on what the student and trainee 'sees' or experiences and 'does'.

$\mathrm{VR}, \mathrm{AR}$, online simulation, serious games, AI and machine learning for medical education are still in their early stages of development. Though these technologies show exciting promise, barriers to widespread use include bulky and expensive devices, small amount of useful interactive content much still in early development stage, and high costs of developing content and workable usable AI [11-16]. As educators, scholars and practitioners, we will need to keep abreast of rapid technological changes and developments. To take full advantage of these technology tools and platforms will require faculty development (in both technology and to deepen our pedagogical skill and knowledge), as well as raising the level of digital literacy in our students and trainees.

One simple, doable, first step for us to take as educators is to (progressively) make our teaching and training material available for review and use online, as (some open access, some restricted access) digital content (following appropriate and accepted professional usage guidelines, including those for professional use, consent, privacy and attribution/ intellectual property). This facilitates use and review by both students and fellow educators, to use and re-use (with attribution). This content can be progressively and systematically curated and indexed by a theme and topic, and ideally also in its most modular, granular form. To encourage, and facilitate re-use, re-purposing and just in time review, for example, key takeaways, recent and topical papers, guidelines, quotes, illustrations, tables, video clips and modular VR and AR content. Our role as teachers, instructors, demonstrators, educators, content creators, curators, editors, filters/screeners/reviewers, guides and coaches can be assisted by AI, informed by digital and learning analytics. As we peek into the future during and after the COVID-19 pandemic, one can imagine us moving from live and recorded video complementing and replacing live teaching to an online first instructional format with ubiquitous and integrated video, and increased use of VR, AR and AI [1, 17, 18].

'As cost progressively reduces, availability and usability of wearable tech for AR, VR, and Mixed Reality progressively increases, together with a deeper understanding of their appropriate use, including software and content for these "newer technologies"; and deeper understanding, wider access, and lower cost of simulation and gaming platforms and paradigms; combined with embedded, usable, and iteratively improving AI and Machine Learning; adoption and use of these technologies to complement, augment, supplement, and even replace previous more traditional methods of instruction and training will progressively increase. Technology will eventually seamlessly integrate even further into our clinical and teaching practice. Our role as educators will be to envision, plan, guide, support and oversee this process, expanding and deepening our role as teachers, instructors, content creators, curators, guides and coaches' [1].

\section{Compliance with Ethical Standards}

Conflict of Interest The author declares that he has no conflicts of interest.

Ethical Approval Not applicable.

Informed Consent Not applicable.

\section{References}

1. Goh PS. Medical educator roles of the future. https:// medicaleducationelearning.blogspot.com/2020/04/iamse-2020plenary-presentation-medical.html. Accessed 18 July 2020.

2. Christensen CM, Hall T, Dillon K, Duncan DS. Know your customers" "jobs to be done". https://hbr.org/2016/09/know-yourcustomers-jobs-to-be-done. Accessed 19 July 2020.

3. Goh PS. A series of reflections on eLearning, traditional and blended learning. MedEdPublish. 2016;5:19. https://doi.org/10.15694/ mep.2016.000105.

4. Goh PS. Technology enhanced learning in Medical Education: what's new, what's useful, and some important considerations. MedEdPublish. 2016;5:16. https://doi.org/10.15694/mep.2016. 000102 .

5. Goh PS. eLearning or technology enhanced learning in medical education - hope, not hype. Med Teach. 2016;38:957-8 http:// www.ncbi.nlm.nih.gov/pubmed/26982639.

6. Gartner Hype Cycle. https://www.gartner.com/en/research/ methodologies/gartner-hype-cycle. Accessed on 19 July 2020. 
7. Goh PS. Adoption of eLearning in Med Ed - costs and value add. https://www.slideshare.net/dnrgohps/adoption-of-elearning-inmed-ed-costs-and-value-add-82738401. Accessed on 19 July 2020.

8. Jones M. 8 Tips for Teaching Online. http://www.bbbpress.com/ 2020/03/8-simple-tips-teaching-online/. Accessed 18 July 2020

9. Goh PS. Effective learning is a repetitive, iterative and cumulative process. https://www.slideshare.net/dnrgohps/effective-learning-isa-repetitive-iterative-cumulative-process. Accessed 18 July 2020.

10. Goh PS. Online learning pathway - progression. https://www. slideshare.net/dnrgohps/online-learning-pathway-progression. Accessed 18 July 2020.

11. Zweifach SM, Triola MM: Extended reality in medical education: driving adoption through provider-centered design. Digit Biomark 2019;3:14-21. doi: 10.1159/000498923. https://www.karger.com/ Article/Fulltext/498923\#

12. Pottle J. Virtual reality and the transformation of medical education. Future healthcare journal. 2019; 6:181-185. https://doi.org/10. 7861/fhj.2019-0036. https://www.ncbi.nlm.nih.gov/pmc/articles/ PMC6798020/

13. Kononowicz AA, Woodham LA, Edelbring S, Stathakarou N, Davies D, Saxena N, et al. Virtual patient simulations in health professions education: systematic review and meta-analysis by the digital health education collaboration. J Med Internet Res. 2019;21(7):e14676 URL: https://www.jmir.org/2019/7/e14676.
14. Sharifzdaeh, N, Tabesh H, Kharrazi H, Edalati M, Heidari S, Tara M. Health education serious games: a scoping review (Preprint). 10.2196/preprints.13459. 2019. https://www.researchgate.net/ publication/330640133_Health_education_serious_games_A_ scoping_review_Preprint

15. Briganti G, Le Moine O. Artificial intelligence in medicine: today and tomorrow. Front Med. 2020;7:27. https://doi.org/10.3389/ fmed.2020.00027 https://www.ncbi.nlm.nih.gov/pmc/articles/ PMC7012990/.

16. Chan KS, Zary N. Applications and challenges of implementing artificial intelligence in medical education: integrative review. JMIR Med Educ. 2019;5(1):e13930 URL: https://mededu.jmir. org/2019/1/e13930.

17. Goh PS. Medical educator roles of the future. https://www. slideshare.net/dnrgohps/medical-educator-roles-of-the-future232394375. Accessed 18 July 2020.

18. Goh PS, Sandars J. A vision of the use of technology in medical education after the COVID-19 pandemic. MedEdPublish. 2020;9: 49. https://doi.org/10.15694/mep.2020.000049.1.

Publisher's Note Springer Nature remains neutral with regard to jurisdictional claims in published maps and institutional affiliations. 